\title{
The Present Situation and Cause Analysis of Education Public Art in Private Universities
}

\author{
Yawei Chen \\ Shaanxi Institute of International Trade \& Commerce, \\ Xi'an, Shaanxi, 712046 \\ e-mail: 56323525@qq.com
}

\author{
Yajun Zhang \\ Changji University, \\ Changji, Xinjiang, 831100 \\ e-mail: 274395832@qq.com
}

\begin{abstract}
This article mainly from the private university public art education status quo, the education concept is backward, the curriculum system is not perfect, the teacher strength is weak, the student quality uneven and so on several aspects of the present situation summary. And then to the formation of this status from the environmental factors, school system, school funding, student characteristics of these four aspects of analysis. And finally summed up some more effective countermeasures: to improve the awareness of public art education in private colleges and universities, from the policy level to support the construction of private characteristics of the public art education system, and public colleges and universities to form a difference; enrich the level of public art courses, highlight the local Artistic characteristics; actively explore to carry out in line with the characteristics of private college students art education activities.
\end{abstract}

\section{Keywords-Private Colleges; Public Art; Artistic Features}

\section{INTRODUCTION}

The present situation and cause analysis of education public art in private universities, In recent years, as the country's emphasis on private colleges and the standardization of the private colleges own development needs, the most private of public art education in colleges and universities have obtained the certain value and show the momentum of rapid development. Most colleges and universities have established public art teaching and research LABS or public art centers, and the number of courses and courses in public art has improved greatly. The minimum number of public art courses in eight private universities in shaanxi province is 12 public art electives per semester, and more than 25 public art electives are offered each semester. With the rapid ascension of non-government university faculty, public art also introduced a large number of high-quality teachers, give priority to with graduate degrees of music, fine arts teachers enrich the field of public art education, to the good development of non-governmental university public art education has laid a solid foundation. However, as a new generation force of education in China, private colleges and universities have some areas to improve in many aspects, so there are many problems in public art that need to be improved.

\section{THROUGH THE RESEARCH OF THE AUTHOR IN}

\section{3-2016, THE FOLLOWING PROBLEMS ARE MAINLY} PRESENT

A. Public art education has developed rapidly, but the concept of public art education has lagged behind

The education system of the private universities in China is centered on "intellectual education", and education is the main direction of education. In recent years, although in theory to improve the college students' humanity quality and the importance of culture in the process of many substantive issues have reached some consensus, the majority of the public art education of private colleges and universities have value and development. Shaanxi institute of international trade, for example, in 2010 opened a public art teaching and research section, to the special public art center, established in 2013, a total investment of more than 200 schools to establish a number of laboratories, introduces four full-time 
public art teacher. The university's investment in public art education has reached unprecedented levels and has been rapidly developed. However, in the specific course setting, there are also the phenomenon of "education of heavy discipline professional, the improvement of light comprehensive quality". The majority of public art courses are taught at night or at weekends, leading to a low attendance rate for most elective students and a form of courses.

But there are also individual private universities public art education has made its own characteristics, even surpassing some public universities. As xi 'an Eurasia college, in 2013, the evaluation of public art in the education department of shaanxi province was highly regarded by experts. Expert group on the summary of feedback is: institute of xi 'an Eurasia can stick to the correct direction of running, earnestly implement the school art education discipline, leadership attention, measures strength, able to art education as important way of implementing quality education and aesthetic education and content. Public art education information is relatively complete and management is orderly; The school hardware, the venue, the student art activity equipment is more advanced, through student forum and teacher forum to the school venue activity evaluation is better; It is worthy of other private universities and even public universities to learn from.

\section{B. No scientific and reasonable curriculum system has}

been formed, and the content lacks local artistic

\section{features}

The investigation found that the public art curriculum of xi 'an private university mainly focused on music, fine arts and film, and mainly focused on the appreciation of the class, which lacked local artistic features. With the rapid development of social economy, the continuous improvement of quality of life people, after some 90 students received a variety of art at an early age, through the survey found that the present college students, since the childhood art education or short-term trained students accounted for more than $50 \%$. Due to improve and enhance their own quality, some of the students is no longer just limited to the general category of appreciation, for some special art knowledge and implementation skills they showed great interest. In the course of the author's teaching, some students showed a keen interest in the shadow art of shaanxi, some interested in clay art, and some students were interested in micro film art. But these art forms are not in public art education's optional course. As a new generation force of colleges and universities in China, private colleges and universities have some autonomy in the process of cultivating talents. The reform and innovation experiment of public art courses can be carried out in a proper way according to the current society needs to make timely revision of the target of personnel training.

\section{The power of the teaching staff is unbalanced and the structure is unreasonable}

Although the ministry of education has made relevant regulations on the teaching staff of education, most of the private universities in xi 'an cannot meet the standards in practice. Take shaanxi international business school as an example, the public art education of the whole school is mainly undertaken by education center of public art and the college of culture and art. There are 20 full-time part-time teachers in public art education, accounting for $0.130 \%$ of the total number of students in the university (below $0.15 \%$ ). If all art professional teachers college of commerce a public course for undergraduate students, the teachers problem can be improved, however, most teachers in for art majors after the commencement of the course, the work has been satisfied or overfulfil, can not effectively solve the shortage of teachers has been.

\section{Art education elitist, public education is not popular}

There is understanding does not reach the designated position, weak teachers, curriculum, teaching content characteristic is not obvious at will, ignore the teaching practice, the second classroom to carry out such outstanding problems as insufficient, lack of policy and safeguard measures, need to relevant departments to strengthen management and protection from the system construction. 
E. Public art education learning quality evaluation system is relatively simple

The current public art education curriculum evaluation target, too much emphasis on the knowledge acquired in the process of teaching, as a result, too much emphasis on knowledge transmission and overlooked the way to get (obtain) knowledge and skills or even acquire knowledge is also a learning quality. It is difficult to cultivate students' creative thinking and independent thinking ability when they evaluate the quality of students. Application type undergraduate colleges and universities, in order to cultivate the ability to serve the local, the service base of the application-oriented talents for the target. Therefore, the evaluation goal should emphasize the process of knowledge and the way knowledge is acquired. The amount of knowledge gained should not be emphasized too narrowly.

In conclusion, that is, private colleges in shaanxi province the current situation of public art education, because the private colleges in newly-built universities and colleges of applied undergraduate, school funds mainly came from the tuition fee income, funds are not well-off, so from the discipline construction, neglect and spending on construction of public art education. Therefore, education of public art in education concept, curriculum setting, teaching staff construction, evaluation system and other aspects of the public colleges and universities have a large gap.

\section{ANALYSIS OF THE MAIN CAUSES OF EDUCATION OF}

\section{PUBLIC ART IN PRIVATE UNIVERSITIES}

\section{A. Group psychology}

Xi'an part of disregard for public art education in colleges and universities, and private undergraduate school has copied public university public art education model, these phenomena, colleges and universities in the region have a significant impact, many colleges and universities are used to herd. At present, most private colleges and universities pay more attention to application type and technical ability in curriculum setting, which is deficient in the cultivation of comprehensive quality of students. Although many colleges and universities put forward the comprehensive quality training of students on the surface, most of the actual operating procedures are reduced to empty words. Some schools have public art courses in their teaching plans, but they do not. Due to this kind of phenomenon is not a special case, the new "go with the flow" of a part of the applied undergraduate colleges, and neglecting the students' comprehensive quality, and even appeared in the teaching plan with public art courses, but it is not open. The second phenomenon is that some private undergraduate colleges and universities have offered courses on public art, but it is the education mode and course content of public art in the public schools. It does not combine the training objectives, curriculum setting and student characteristics of private colleges and universities to make education special in public art.

\section{B. The school system}

New applied undergraduate colleges and universities use the director responsibility system under the leadership of the board of directors, more education funds in bull management, earnings judgment model, this model on the investment of public art education has obvious limitation.

\section{The cost of running}

A school depends on the tuition fee for all the expenses of newly-built applied undergraduate colleges, so the fund dependence is too large, which causes the investment in education to be cautious and cautious.

D. Characteristics of students is a very important factor in the process of education

College students in adolescence have the characteristics of active thinking, learning ability and innovation and entrepreneurial ability. However, students in applied universities have their own unique characteristics according to practical observation. Active and distinct personality, able to actively participate in the various activities of the school of college students, the social activities ability and participation consciousness is stronger. Relative to the universities students, private colleges students have strong consciousness of participation, the students, school youth corps committee, student community organization of all kinds of campaign activities and cultural activities showed 
great enthusiasm, promoting school thriving entertainment activities. Take the international trade of shaanxi province as an example, the 2015 school's various literary and artistic performances, entertainment events as many as 100. Many students focus too much on extracurricular activities and neglect their focus on professional learning. This is their advantage, and they also have many shortcomings.

\section{1) Self-inferiority, great pressure and lack of good self-management ability}

Private undergraduate colleges and universities are usually three universities in the sense that students are mentally stressed, mentally weak, sensitive and vulnerable, sometimes confused and frustrated. The author observed that many college students to school, at the same time of inferiority, full of ambition, learning seriously hard, good comprehensive study plan, believe in yourself by learning from private colleges for further study, have a bright future development; Inferiority complex, on the other hand, has the upper hand, thought pressure is big, the three colleges and universities student's identity for himself and feel upset, often fall into a state of confusion, need to continuously encourage teachers, lack of good self motivation management ability. Part of the effects of these factors, the students at the beginning of the great ideal, grand ambitions, finally kill by realistic fragile, part of the students by positive learning attitude to deal with the concept of this kind of phenomenon is common in private colleges and universities.

2) Strong self-esteem, weak self-confidence and lack of good study habits
According to the observation, students in applied colleges show strong self-esteem. In terms of learning, I can't face up to my shortcomings in learning methods and learning habits, and I am too self-centered. They are eager to be sure and supportive of their teachers and classmates, but they reject the advice of teachers and classmates. In terms of life, a few students have obvious comparison psychology, which is the common problem of teenagers, but it is more obvious in the three schools. In addition, there is discrimination in all aspects of the society, and students from three universities have fewer opportunities to get the internship and employment than the students of one or two. Therefore, students are not motivated to learn.

\section{CONCLUSION}

To sum up, the private schools to take advantage of higher schools' development of public art education opportunities, according to their own conditions and requirements, adjust measures to local conditions, flexible and effective, pragmatic and innovative public art education, really improve the quality of personnel training, improve the quality and level of private colleges and universities.

[1] Art in America, May Issue 2007

[2] F. ZeublinCreative Currents-The ArtInstitute of Chicago, 2006-2007

[3] James Elkins, Why Art Cannot Be Taught, Urbana, Chicago, 2001

[4] Liu Wei nationalism concept: the development trend of foreign public art education and the exploration of enlightenment education, 2007

[5] Discussion on the standardization construction of public art education in colleges and universities 